\title{
The relationship between implied volatility and cryptocurrency returns
}

\begin{abstract}
We analyse the relationship between the price volatility of a broad range of cryptocurrencies and that of implied volatility of both United States and European financial markets as measured by the VIX and VSTOXX respectively. Overall, our results indicate the existence of time-varying positive interrelationships between the conditional correlations of cryptocurrencies and financial market stress. Further, these correlations are found to increase substantially during periods of high financial market stress, indicating that the contagion of significant financial market fear influences these new financial products.
\end{abstract}

Keywords: Cryptocurrencies; Volatility; VIX; VSTOXX; GARCH; DCC-GARCH.

\section{Introduction}

The interactions between cryptocurrencies and broader financial market products has been a source of significant debate during the speculative product's short existence. While Corbet et al. [2019] have provided a concise systematic review of the literature associated with cryptocurrency markets at large, they note the broad variety in research that provides evidence outlining improvements in the market efficiency of cryptocurrencies. Tiwari et al. [2018] identify significant periods of pricing inefficiency during the life of Bitcoin, echoing the results provided by Urquhart [2016], Nadarajah and Chu [2017] and Bariviera [2017] who found, using a Hurst exponent calculated during overlapping sliding windows, that the daily return time series become more efficient across time and that the daily volatility exhibits long-range memory during the sample period of investigation. Brauneis and Mestel [2018] found that the pricing efficiency of Bitcoin is positively related to liquidity. Urquhart [2017] found evidence of clustering at round numbers, with over $10 \%$ of prices ending with 00 decimals, but no significant pattern of returns after the round number.

Further, Corbet et al. [2018] found evidence of the relative isolation of cryptocurrencies from the traditional financial and economic assets, presenting evidence of the diversification benefits for investors with short investment horizons. Baur et al. [2018] identify that statistically Bitcoin is not a hybrid of both a commodity and fiat currency, and that the returns, volatility and correlation characteristics of Bitcoin are distinctively different compared to gold and the US dollar. Dyhrberg [2016] found several similarities between Bitcoin, gold and the dollar indicating hedging capabilities and advantages as a medium of exchange. There has also been increased attention paid on the interactions between cryptocurrencies 
and other financial market products such as futures markets. Corbet et al. [2018] found that the introduction of Bitcoin futures actually generated a destabilising mechanism which increased the volatility of the cryptocurrency ${ }^{1}$ All of this research has developed while in the background, market integrity has been challenged by questions surrounding regulatory ambiguity (Fry [2018]; Corbet et al. [2019]), and exceptional levels of both complex and uncomplex fraud (Gandal et al. [2018]; Corbet et al. [2019]).

Overall, we build upon the previous literature by showing that cryptocurrencies present evidence of substantial volatility during periods of time where investor's 'fear' is elevated. We find that not only has cryptocurrency volatility shown evidence of correlation with volatility products during such elevated implied volatility events with such comovement representing a strong signal of shared contagion Forbes and Rigobon [2002], but cryptocurrencies present evidence of strong increases in volatility during the highest deciles that incorporate the largest levels of forward looking fear in both the United States and Europe respectively.

\section{Data and Methodology}

In this study, we use dollar-denominated cryptocurrency close-price data at thirtyminute intervals from the Bitfinex exchange. The exchange was selected due to it's longstanding international reputation, but also due to the exchange's continued top-rank by normalised trading volume throughout the investigated period. We obtain the price data from the Kaiko digital asset store. Our dataset entails the period from midnight on 22 June 2017 through midnight on the 24 June 2018, which represents a period incorporating 17,472 observations. Figure 1 shows the volatility signature plot which provides the average of three realized volatility estimators at 5-, 10-, 15-, 30-, and 60-minute sampling frequencies (see Sevi [2014] for further details). As it is clear from the figure, for almost all of the coins, these three measures decrease with the increasing frequency. Together with this fact, we observe from Table 1 that the percentage of the number of missing values to the number of whole points decreases with the increasing frequency. Hence, we choose 30-min interval as to have a low percentage of missing values and at the same time as to have an enough number of observations to draw meaningful conclusions from our analysis.

The use of high-frequency data enables a thorough analysis of volatility dynamics between our selected twenty-two cryptocurrencies sorted by largest market capitalisation and

\footnotetext{
${ }^{1}$ Further, much literature has focused on key questions, such as whether Bitcoin is a currency or speculative asset (Corbet et al. [2019b]), the dynamics of pricing volatility (Katsiampa et al. [2019]; Corbet and Katsiampa [2019]), as to whether there exist pricing inefficiencies (Sensoy [2019], Mensi et al. [2019], Corbet et al. [2019]), whether Bitcoin is in isolation from other traded assets (Corbet et al. [2018]; Corbet et al. [2019a]), the development of derivative products (Corbet et al. [2018]; Akyildirim et al. [2019]), and as to whether there is pricing bubbles in these new markets (Corbet et al. [2018]).
} 
liquidity $^{2}$. Our selected volatility indices include the VIX (CBOE-traded) and VSTOXX (DAX-traded), denoting measures of United States and European financial market risk respectively. Both represent real-time options prices and are both designed to reflect the market expectations near-term through long-term volatility by measuring the square root of the implied variance across all options of a given time to expiration. Interactions between such forward-looking implied volatility measures and cryptocurrencies would represent an interesting development. Our thirty-minute returns are calculated as:

$$
r_{t, m}=\left(\ln r_{t, m}-\ln r_{t, m-1}\right) \mathrm{x} 100
$$

where $r_{t, m}$ is the return for minute $\mathrm{m}$ on trading day $\mathrm{t}$. Time periods with no trading activity are determined to be best represented by the last traded price. To analyse the dynamic correlations between our selected cryptocurrencies and both the VIX and VSTOXX, we employ a standard GARCH $(1,1)$ methodology of Bollerslev [1986] and extract dynamic conditional correlations (of Engle [2002]) that takes the form:

$$
\begin{gathered}
r_{t}=\alpha_{t}+\sum_{j=1}^{t} \sigma r_{t-j}+b_{t}+\sum_{j=1}^{t} \eta b_{t-j}+d j_{t}+\sum_{j=1}^{t} \gamma v_{t-j}+u_{t} \\
\sigma_{t}^{2}=\alpha_{0}+\alpha_{1} \varepsilon_{t-1}^{2}+\beta_{1} \sigma_{t-1}^{2}
\end{gathered}
$$

where $k_{t}, b_{t}$ and $v_{t}$ are the returns of the investigated cryptocurrency, Bitcoin and VIX/VSTOXX at time $t$ respectively. $\sigma, \eta$ and $\gamma$ represent the effects of lagged returns of each selected variable on the returns of the cryptocurrency's thirty-minute price volatility. The variance equation includes the long-term average volatility $\alpha_{0}$. We explore the dynamic co-movements via the dynamic conditional correlations of Engle [2002]. The GARCH $(1,1)$ specification requires that in the conditional variance equation, parameters $\alpha_{0}, \alpha_{1}$ and $\beta$ should be positive for a non-negativity condition and the sum of $\alpha_{1}$ and $\beta$ should be less than one to secure the covariance stationarity of the conditional variance. Moreover, the sum of the coefficients $\alpha_{1}$ and $\beta$ must be less than or equal to unity for stability to hold.

Next, we sub-divide both the VIX and VSTOXX respectively into deciles based on the calculated thirty-minute volatility. For example, decile one represents the lowest calculated volatility estimates while decile ten represents the largest. The deciles are presented in

\footnotetext{
${ }^{2}$ Our selected cryptocurrencies include Aventus (AVT), Bitcoin Cash (BCH), Bitcoin (BTC), Bitcoin Gold (BTG), Datum (DAT), Dash (DSH), Eidoo (EDO), EOS (EOS), Ethereum (ETH), Metaverse ETP (ETP), Iota (IOT), Litecoin (LTC), NEO (NEO), OmiseGO (OMG), QASH (QSH), Qtum (QTM), Recovery Right Tokens (RRT), Santiment Network Token (SAN), Monero (XMR), Ripple (XRP), YOYOW (YYW) and Zcash (ZEC) respectively.
} 
Figure 2 with the performance of both the VIX and VSTOXX. Specification tests found that the GARCH $(1,1)$ model served as the best fitting to estimate cryptocurrency volatility dynamics. It is also necessary to mitigate both international effects and sectoral effects which can be completed through the inclusion of the returns of traditional financial products and key cryptocurrency returns in the mean equation of the $\operatorname{GARCH}(1,1)$ methodology. The volatility sourced in shocks that are incorporated in the returns of these markets are therefore considered in the volatility estimation of the selected structure. Dummy variables are used in the variance equation denoted as unity when the decile of VIX and VSTOXX volatility has been identified and zero otherwise. The lagged cryptocurrency returns for the eight following thirty-minute period were found to provide explanatory significance and are therefore included in the mean equation. The GARCH $(1,1)$ methodology used in this study has the following form:

$$
\begin{gathered}
R_{t}=a_{0}+\sum_{j=1}^{8} b_{j} R_{t-j}+b_{2} B T C_{t}+b_{3} V_{t}+b_{4} E T H_{t}+b_{5} L T C_{t}+\varepsilon_{t} \\
\varepsilon_{t} \mid \Omega_{t} \sim i . i . d . \quad N\left(0, h_{t}\right) \\
h_{t}=\omega+\alpha_{1} h_{t-1}+\beta_{1} u_{t-1}^{2}+\sum_{i=1}^{10} D_{v}
\end{gathered}
$$

$R_{t-j}$ represents the lagged value of the selected cryptocurrency returns, $j$ number of thirty-minute periods before $R_{t}$ is observed. $b_{2} B T C_{t}$ represents the interaction between the selected cryptocurrency returns and Bitcoin with the exception of the methodology based on Bitcoin returns, while $b_{3} V_{t}$ represents the value of the VIX (or VSTOXX) in the thirty minute period that the estimate $R_{t}$ was observed. Finally, $b_{4} E T H_{t}$ and $b_{5} L T C$ represent the relationship between the investigated cryptocurrency returns and the returns of both ETH and LTC respectively with the exception of the methodologies that are specific to both. $\sum_{i=1}^{10} D_{v}$ is included in the variance equation to provide a coefficient relating the included ten dummy variables to the decile of volatility within which each of the thirtyminute cryptocurrency observations fall as denoted in Figure 2. Bollerslev [1986] argued for restrictions on the parameters for positivity, $\omega>0, \alpha \geq 0$ and $\beta \geq 0$, and the wide-sense stationarity condition, $\alpha+\beta<1$. While the GARCH $(1,1)$ process is uniquely stationary if $E\left[\log \left(\beta+\alpha \epsilon_{t}^{2}\right)\right]<0$, Bollerslev [1986] also proved that if the fourth order moment exists, then the model can handle leptokurtosis. Bonferroni adjusted results are presented in this analysis. To cater the multiple hypothesis problem, we adjust the significance level using the Bonferroni correction, which leads to a significance level of $0.1 \%$. The generalised Bonferroni method adjusts the significance level such that hypothesis $H_{0,(i)}, i=1, \ldots, s$, is deemed rejected if and only if:

$$
\hat{p}_{(i)} \leq \alpha_{(i)} \equiv k \cdot \alpha / s .
$$


This procedure has the advantage of being robust to the dependence structure of the hypothesis tests.

\section{Empirical Results}

The segregation of both the VIX and VSTOXX into deciles to be used in this analysis is presented in Figure 2. It is evident that in January 2018, a strong stock market correction in the United States generated a sharp, but temporary increase in both metrics measuring implied volatility. The Dow Jones posted it's worst weekly returns since early 2016 dropping almost 6\%. Figures 3 and 4 present evidence of the dynamic correlations between our selected cryptocurrencies and the VIX and VSTOXX respectively. Throughout all the analysed relationships, we observe a number of sharp increases and declines in correlations in the period surrounding the January 2018 stock market correction. These changes follow substantial evidence of minimal correlations in the period prior to January 2018. It is of interest that analysed cryptocurrencies appear to respond in a variety of different ways, however, in the period between January 2018 and June 2018, there is evidence of substantially elevated correlations between cryptocurrencies and stock market implied volatility.

Further, Tables 2 and 3 present evidence of the volatility changes of our selected cryptocurrencies during the denoted deciles of both the VIX and VSTOXX respectively. The selected GARCH-specification presents strong positive correlations between the included cryptocurrencies, however, little or no correlations with the VIX and VSTOXX when calculated during the entire period of investigation. With regards to the VIX, we identify significant elevations in volatility at higher deciles in the markets for AVT, BCH, BTC, DAT, EOS, LTC, QTM, RRT and ZEC. The European measure of implied volatility, or VSTOXX, presents evidence of substantially elevated cryptocurrency volatility in higher deciles for the markets for BCH, BTC, BTG, DAT, EDO, EOS, ETH, ETP, LTC, SAN and YYM. The lowest deciles of implied volatility are found to present little or no significant volatility transition throughout our selected methodologies and financial market products. While much research identifies the lack of correlations between cryptocurrencies and traditional financial markets as a desirable feature when seeking alternative investment vehicles in an attempt to increase portfolio diversification. However, the above research presents evidence that such added diversification might not exist during periods of stock market turmoil that results in elevated levels of implied stock market volatility as measured by the VIX and VSTOXX respectively. In periods of extreme volatility, there is evidence to suggest that not only do cryptocurrencies experience sharp increases in volatility, but also significant elevation in the correlations of their returns although temporary. Further, this evidence supports the continued development of cryptocurrencies as a growing and viable

financial market asset class due to its shared characteristics with common products such as stocks, currencies, bonds and commodities. 


\section{Concluding Comments}

Our research indicates that cryptocurrencies are found to present evidence of increased volatility during periods of time where investors' 'fear' is elevated. We find that not only has cryptocurrency volatility presented evidence of substantial correlations with volatility products such as the VIX and VSTOXX during such elevated implied volatility events, but cryptocurrencies themselves present evidence of strong increases in GARCH-calculated volatility during the highest deciles of stock market implied volatility, incorporating the largest levels of forward looking fear in both the United States and Europe respectively. While there exists conflicting evidence with regards to the interactions between cryptocurrencies and a number of international financial market products, using high frequency data across a range of liquid, highly-capitalised cryptocurrencies, we identify that there exists evidence supporting the influence of option denoted implied volatility on the price volatility of this new financial product.

\section{Bibliography}

Akyildirim, E., S. Corbet, P. Katsiampa, N. Kellard, and A. Sensoy (2019). The birth of futures markets: Exploring the interactions between cryptocurrency derivatives. Available at $S S R N$.

Bariviera, A. F. (2017). The inefficiency of Bitcoin revisited: A dynamic approach. Economics Letters 161, 1-4.

Baur, D. G., T. Dimpfl, and K. Kuck (2018). Bitcoin, gold and the us dollar-a replication and extension. Finance Research Letters 25, 103-110.

Bollerslev, T. (1986). Generalized autoregressive conditional heteroskedasticity. Journal of Econometrics 31(3), 307-327.

Brauneis, A. and R. Mestel (2018). Price discovery of cryptocurrencies: Bitcoin and beyond. Economics Letters 165, 58-61.

Corbet, S., D. J. Cumming, B. M. Lucey, M. Peat, and S. Vigne (2019). Investigating the dynamics between price volatility, price discovery, and criminality in cryptocurrency markets. Available at SSRN.

Corbet, S., V. Eraslan, B. M. Lucey, and A. Sensoy (2019). The effectiveness of technical trading rules in cryptocurrency markets. Finance Research Letters 31, 32-37.

Corbet, S. and P. Katsiampa (2019). Asymmetric mean reversion of Bitcoin price returns. International Review of Financial Analysis Forthcoming. 
Corbet, S., C. J. Larkin, B. M. Lucey, A. Meegan, and L. Yarovaya (2019a). Cryptocurrency reaction to FOMC announcements: Evidence of heterogeneity based on blockchain stack position. Available at SSRN.

Corbet, S., C. J. Larkin, B. M. Lucey, A. Meegan, and L. Yarovaya (2019b). The volatility generating effects of macroeconomic news on cryptocurrency returns. Available at SSRN.

Corbet, S., C. J. Larkin, B. M. Lucey, and L. Yarovaya (2019). Kodakcoin: A blockchain revolution or exploiting a potential cryptocurrency bubble? Applied Economics Letters (forthcoming).

Corbet, S., B. Lucey, M. Peat, and S. Vigne (2018). Bitcoin futures: What use are they? Economics Letters 172, 23-27.

Corbet, S., B. Lucey, and L. Yarovaya (2018). Datestamping the Bitcoin and Ethereum bubbles. Finance Research Letters 26, 81-88.

Corbet, S., B. M. Lucey, A. Urquhart, and L. Yarovaya (2019). Cryptocurrencies as a financial asset: A systematic analysis. International Review of Financial Analysis 62, $182-199$.

Corbet, S., A. Meegan, C. Larkin, B. Lucey, and L. Yarovaya (2018). Exploring the dynamic relationships between cryptocurrencies and other financial assets. Economics Letters 165, $28-34$.

Dyhrberg, A. H. (2016). Bitcoin, gold and the dollar-a garch volatility analysis. Finance Research Letters 16, 85-92.

Engle, R. (2002). Dynamic conditional correlation: A simple class of multivariate generalized autoregressive conditional heteroskedasticity models. Journal of Business $\&$ Economic Statistics 20(3), 339-350.

Forbes, K. J. and R. Rigobon (2002). No contagion, only interdependence: Measuring stock market comovements. The Journal of Finance 57(5), 2223-2261.

Fry, J. (2018). Booms, busts and heavy-tails: The story of Bitcoin and cryptocurrency markets? Economics Letters 171, 225-229.

Gandal, N., J. Hamrick, T. Moore, and T. Oberman (2018). Price manipulation in the Bitcoin ecosystem. Journal of Monetary Economics 95, 86-96.

Katsiampa, P., S. Corbet, and B. Lucey (2019). Volatility spillover effects in leading cryptocurrencies: A BEKK-MGARCH analysis. Finance Research Letters, 29, 68-74. 
Mensi, W., Y.-J. Lee, K. H. Al-Yahyaee, A. Sensoy, and S.-M. Yoon (2019). Intraday downward/upward multifractality and long memory in Bitcoin and Ethereum markets: An asymmetric multifractal detrended fluctuation analysis. Finance Research Letters 31, $19-25$.

Nadarajah, S. and J. Chu (2017). On the inefficiency of Bitcoin. Economics Letters 150, $6-9$.

Sensoy, A. (2019). The inefficiency of Bitcoin revisited: A high-frequency analysis with alternative currencies. Finance Research Letters, 28, 68-73.

Sevi, B. (2014). Forecasting the volatility of crude oil futures using intraday data. European Journal of Operational Research 235, 643-659.

Tiwari, A. K., R. Jana, D. Das, and D. Roubaud (2018). Informational efficiency of Bitcoin: An extension. Economics Letters 163, 106-109.

Urquhart, A. (2016). The inefficiency of Bitcoin. Economics Letters 148, 80-82.

Urquhart, A. (2017). Price clustering in Bitcoin. Economics letters 159, 145-148. 
Figure 1: Volatility signature plot for the included cryptocurrencies
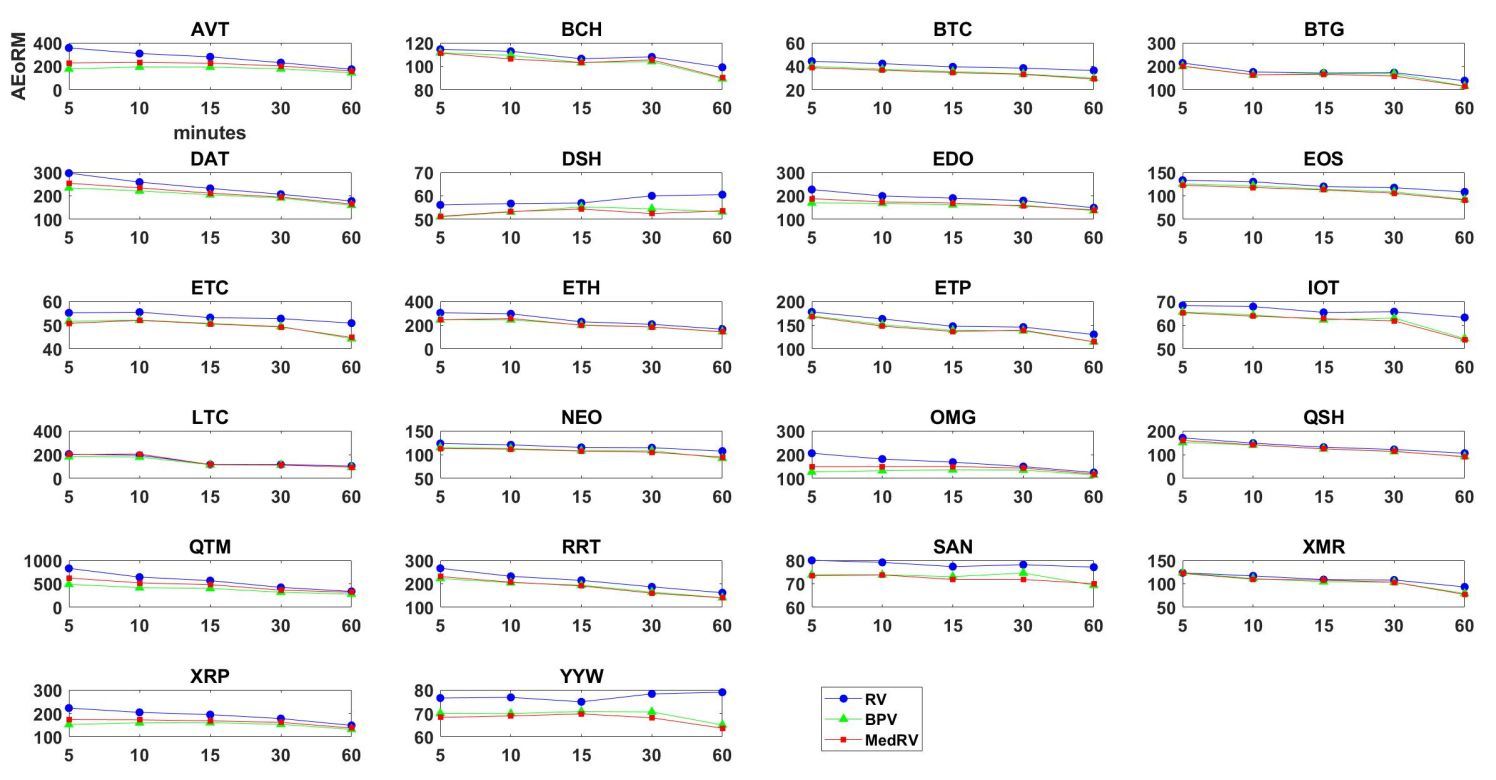

Note: The above figures present the volatility signature plot for the included cryptocurrencies realised volatility, bipower variation and median realised estimators. AEoRM stands for the avergae estimate of realized measure 
Figure 2: VIX and VSTOXX price performance
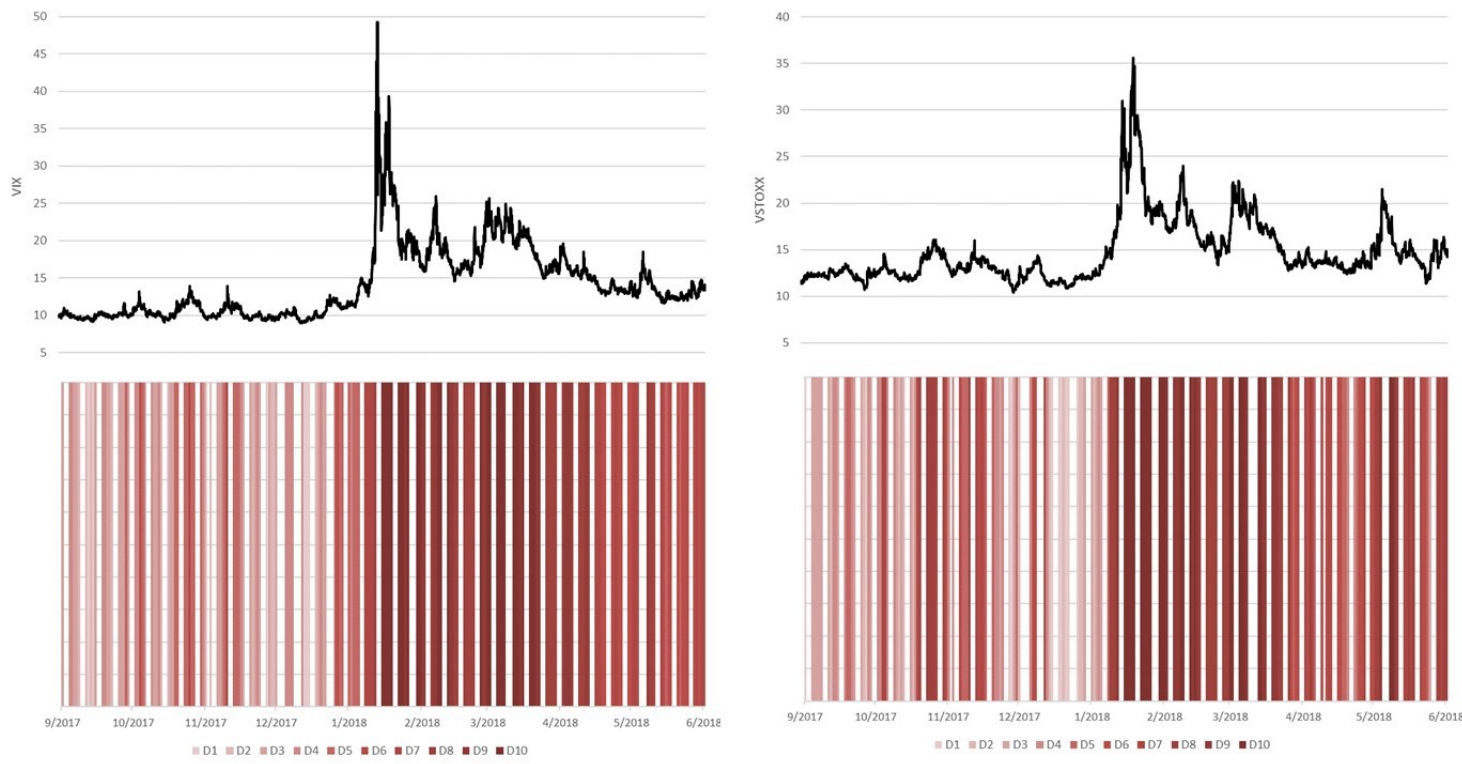

Note: The above figures presents the price performance and time-denoted deciles for both the VIX and VSTOXX between June 2017 and June 2018. 
Figure 3: Dynamic correlations between selected cryptocurrencies and the VIX
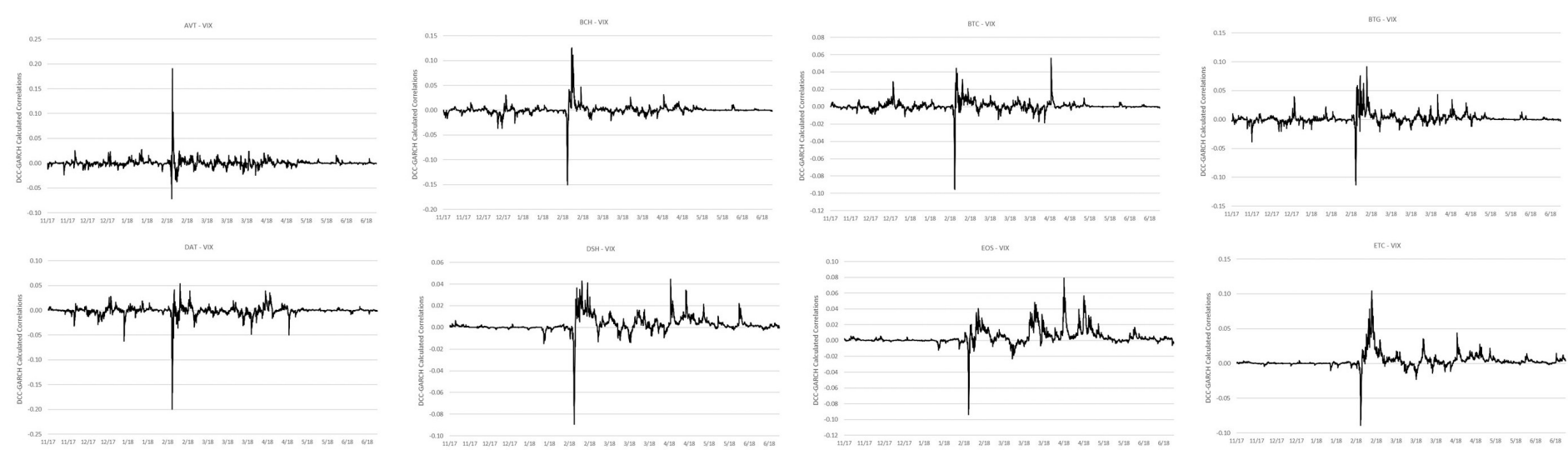

๒
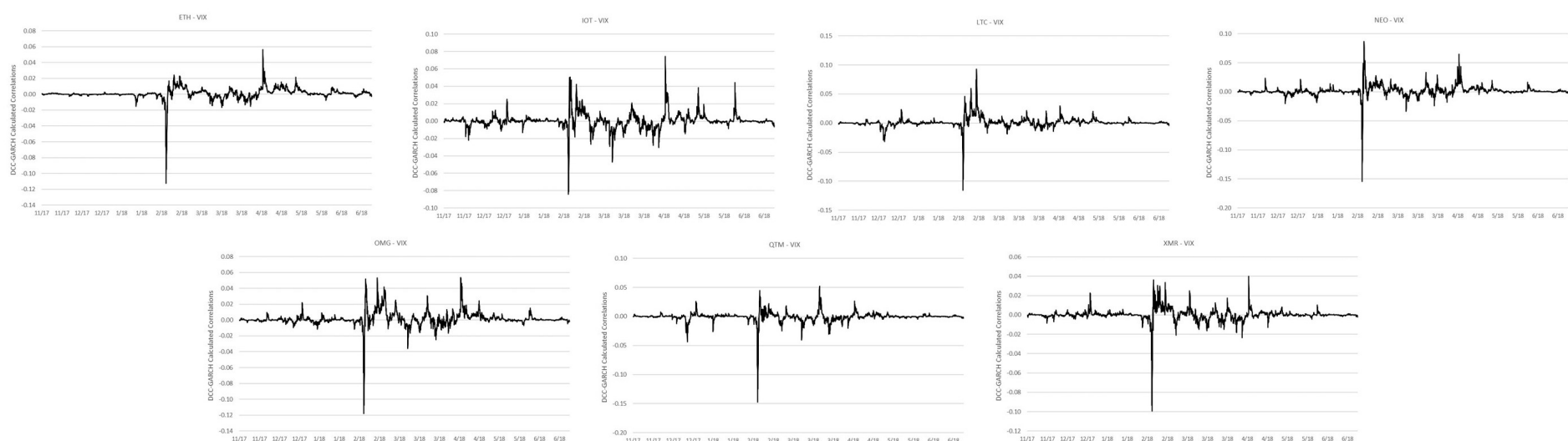

Note: The presented analysis was conducted using 30 minute data between midnight on 22 June 2017 and 11:30 pm on 23 June 2018. Further cryptocurrency results are available from the authors on request. 
Figure 4: Dynamic correlations between selected cryptocurrencies and the VSTOXX
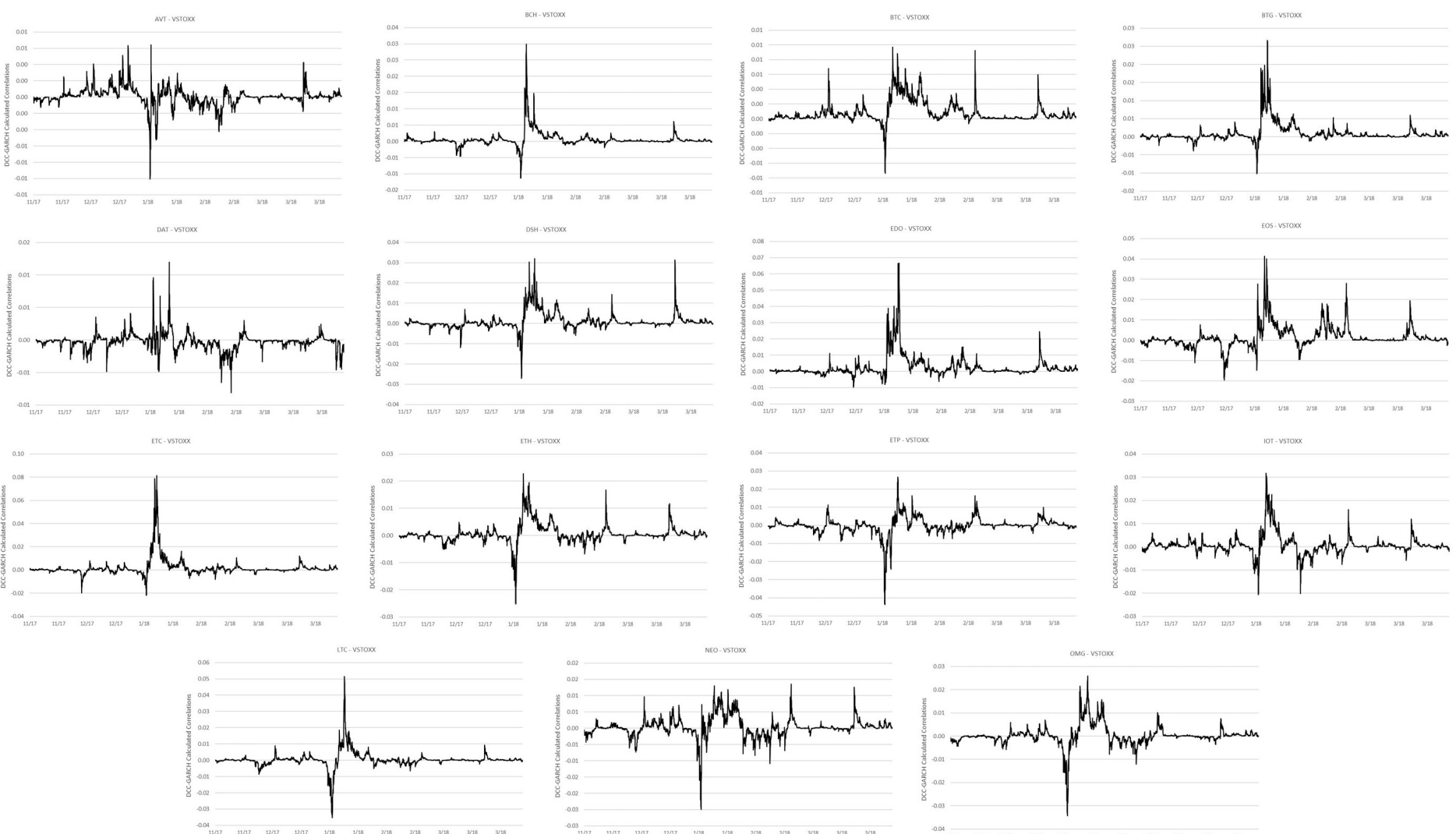

Note: The presented analysis was conducted using 30 minute data between midnight on 22 June 2017 and 11:30 pm on 23 June 2018. Further cryptocurrency results are available from the authors on request. 
Table 1: Percentage of the number of missing values to the number of all points in the chosen period of study

\begin{tabular}{cccccccccccc}
\hline \hline & AVT & BCH & BTC & BTG & DAT & DSH & EDO & EOS & ETH & ETP & IOT \\
\hline 1-min & 83.09 & 10.01 & 4.25 & 32.56 & 58.52 & 35.00 & 68.89 & 11.49 & 1.94 & 51.69 & 7.98 \\
5-min & 57.07 & 1.17 & 3.42 & 6.88 & 27.45 & 6.21 & 35.08 & 1.53 & 1.05 & 19.67 & 1.04 \\
10-min & 43.39 & 0.81 & 2.79 & 2.51 & 15.78 & 1.83 & 21.59 & 0.85 & 1.00 & 10.48 & 0.81 \\
15-min & 35.79 & 0.77 & 2.33 & 1.42 & 10.49 & 0.96 & 14.85 & 0.75 & 0.96 & 6.82 & 0.78 \\
30-min & 23.66 & 0.73 & 1.40 & 0.73 & 4.36 & 0.62 & 7.05 & 0.67 & 0.91 & 2.90 & 0.74 \\
60-min & 13.07 & 0.66 & 0.76 & 0.53 & 1.96 & 0.51 & 2.95 & 0.60 & 0.82 & 1.21 & 0.66 \\
\hline & LTC & NEO & OMG & QSH & QTM & RRT & SAN & XMR & XRP & YYW & ZEC \\
\hline 1-min & 7.71 & 17.76 & 20.85 & 73.15 & 59.52 & 85.57 & 53.58 & 32.66 & 9.48 & 71.29 & 32.88 \\
5-min & 0.91 & 2.09 & 3.53 & 46.00 & 27.37 & 62.52 & 19.77 & 5.97 & 1.33 & 43.28 & 5.31 \\
10-min & 0.71 & 0.91 & 1.62 & 32.36 & 15.37 & 48.90 & 9.48 & 2.06 & 0.79 & 29.78 & 1.70 \\
15-min & 0.68 & 0.78 & 1.24 & 24.66 & 10.10 & 40.43 & 5.51 & 1.22 & 0.74 & 22.41 & 0.94 \\
30-min & 0.64 & 0.71 & 1.02 & 13.36 & 4.24 & 25.99 & 1.85 & 0.80 & 0.67 & 12.34 & 0.66 \\
60-min & 0.58 & 0.64 & 0.91 & 5.59 & 1.82 & 14.04 & 0.76 & 0.67 & 0.60 & 5.47 & 0.55 \\
\hline \hline
\end{tabular}


Table 2: Cryptocurrency performance during differing deciles of VIX volatility

\begin{tabular}{|c|c|c|c|c|c|c|c|c|c|c|c|}
\hline$R_{1}$ & $\begin{array}{c}\text { AVT } \\
-02594^{* * * *}\end{array}$ & BCH & $\begin{array}{c}\text { BTC } \\
-0259^{* *}\end{array}$ & BTG & $\begin{array}{c}\text { DAT } \\
\end{array}$ & DSH & EDO & EOS & ETH & ETP & IOT \\
\hline $\begin{array}{l}R_{t-1} \\
R_{t-2}\end{array}$ & $\begin{array}{c}-0.2594^{* * * *} \\
-0.1149^{* * * *}\end{array}$ & $\begin{array}{c}-0.0169^{*} \\
-0.0064\end{array}$ & $\begin{array}{c}-0.0259^{* *} \\
0.0160\end{array}$ & $\begin{array}{l}-0.0183 \\
-0.0116\end{array}$ & $-0.0895^{* * * *}$ & $0.0271^{* * * * *}$ & $-0.0907^{* * * *}$ & $-0.0446^{* * * *}$ & 0.0128 & $-0.1354^{* * * *}$ & 0.0048 \\
\hline $\begin{array}{l}R_{t-2} \\
R_{t-3}\end{array}$ & $\begin{array}{l}-0.1149^{* * * *} \\
-0.1169 * * * *\end{array}$ & $\begin{array}{c}-0.0064 \\
-0.0430 * * * *\end{array}$ & $\begin{array}{c}0.0160 \\
-0.0203^{* *}\end{array}$ & $\begin{array}{l}-0.0116 \\
-0.0024\end{array}$ & $\begin{array}{l}-0.0525^{* *} \\
-0.0450^{* *}\end{array}$ & $\begin{array}{l}0.0009 \\
-0.0309 * * *\end{array}$ & $-0.0325^{*}$ & $-0.0212^{*}$ & $-0.0247^{* * *}$ & $-0.0432^{* * * *}$ & $-0.0368^{* * * *}$ \\
\hline $\begin{array}{l}n_{t-3} \\
R_{t-4}\end{array}$ & $\begin{array}{l}-0.1109 \\
-0.0775 * * * *\end{array}$ & $\begin{array}{c}-0.0430 \\
-0.0027\end{array}$ & $\begin{array}{l}-0.020009 \\
-0.0009\end{array}$ & $\begin{array}{l}-0.0024 \\
-0.0150\end{array}$ & $\begin{array}{r}-0.0450 \\
-0.0163\end{array}$ & $\begin{array}{c}-0.03096 \\
0.0064\end{array}$ & $\begin{array}{l}-0.0018 \\
-0.071 * * * *\end{array}$ & $-0.0303^{*}$ & $-0.0329^{* * *}$ & -0.0005 & 0.0124 \\
\hline $\begin{array}{l}R_{t-5} \\
R_{t-5}\end{array}$ & -0.0254 & $-0.0287^{* * * *}$ & -0.0052 & -0.0149 & $-0.0659^{* * *}$ & 0.0047 & -0.0227 & $\begin{array}{l}-0.0077 \\
-0.0265^{* *}\end{array}$ & $\begin{array}{l}-0.0109 \\
-0.0084\end{array}$ & $-0.0333^{* *}$ & -0.0059 \\
\hline$R_{t-6}$ & -0.0093 & $0.0281^{* * * *}$ & $0.0236^{* * *}$ & 0.0036 & 0.0005 & 0.0043 & 0.0030 & 0.0105 & 0.0074 & -0.0141 & $0.0471^{* * *}$ \\
\hline$R_{t-7}$ & $-0.0409 * * *$ & -0.0051 & -0.0074 & -0.0137 & $0.0355^{* *}$ & $0.0181^{* *}$ & -0.0148 & -0.0125 & -0.0095 & 0.0092 & $-0.0290 * * *$ \\
\hline$R_{t-8}$ & $-0.0620^{* * * *}$ & $-0.0152^{*}$ & 0.0049 & -0.0117 & -0.0184 & $-0.0203^{* *}$ & -0.0040 & -0.0118 & 0.0057 & $-0.0225^{*}$ & $0.0205^{* *}$ \\
\hline BTC & $0.3742^{* * * *}$ & $0.5769^{* * * *}$ & & $0.4478^{* * * *}$ & $0.4358^{* * * *}$ & $0.4185^{* * *}$ & $0.5015^{* * * *}$ & $0.5770^{* * * *}$ & $0.3224 * * *$ & $0.4304^{* * * *}$ & $0.5235^{* * * *}$ \\
\hline VSTOXX & $0.0005^{* * * *}$ & $-0.0001 *$ & 0.0000 & 0.0000 & -0.0001 & 0.0001 & 0.0001 & 0.0001 & 0.0001 & $-0.0003^{*}$ & 0.0001 \\
\hline ETH & $0.0790^{* * * *}$ & $0.1586^{* * * *}$ & $0.2140^{* * *}$ & $0.2824^{* * *}$ & $0.1941^{* * * *}$ & $0.1617^{* * *}$ & $0.1734^{* * *}$ & $0.2580^{* * * * *}$ & 0.000 & $0.6093^{* * * *}$ & $0.5659^{* * * *}$ \\
\hline LTC & $0.1180^{* * * *}$ & $0.1904^{* * *}$ & $0.4123^{* * * *}$ & $0.2090 * * *$ & $0.2169^{* * * *}$ & $0.2336^{* * *}$ & $0.1088^{* * *}$ & $0.1794^{* * * *}$ & $0.1809^{* * *}$ & $0.0837^{* * *}$ & $0.1133^{* * * *}$ \\
\hline 1st Dec & 0.0023 & 0.0023 & 0.0024 & 0.0032 & 0.0039 & $0.0147^{* * *}$ & 0.0004 & 0.0006 & 0.0015 & $0.0045^{* * * *}$ & 0.0031 \\
\hline 2nd Dec & 0.0025 & 0.0013 & $0.0043^{* *}$ & 0.0003 & 0.0000 & $0.0102^{* * * *}$ & 0.0058 & 0.0012 & 0.0025 & $0.0040^{* * * *}$ & 0.0044 \\
\hline 3rd Dec & 0.0042 & 0.0007 & 0.0015 & 0.0030 & 0.0025 & $0.0111^{* * *}$ & 0.0059 & 0.0051 & 0.0034 & $0.0034^{* * *}$ & 0.0040 \\
\hline 4th Dec & $0.0101^{* *}$ & $0.0052^{* * *}$ & 0.0017 & 0.0022 & 0.0050 & $0.0131^{* * *}$ & 0.0028 & 0.0024 & $0.0055^{* *}$ & $0.0040^{* * *}$ & 0.0065 \\
\hline 5th Dec & $0.0051 *$ & $0.0025 *$ & 0.0015 & 0.0022 & 0.0025 & $0.0112^{* * *}$ & 0.0019 & 0.0030 & 0.0027 & $0.0035^{* * *}$ & $0.0079 * *$ \\
\hline 6th Dec & $0.0051 *$ & $0.0030^{*}$ & $0.0056^{* * *}$ & 0.0026 & 0.0014 & $0.0126^{* * *}$ & 0.0012 & $0.0039^{* * *}$ & 0.0024 & $0.0036^{* * * *}$ & $0.0042^{*}$ \\
\hline 7th Dec & $0.0050^{*}$ & $0.0028^{* *}$ & $0.0064 * * * *$ & 0.0046 & 0.0089 & $0.0102 * * *$ & 0.0012 & 0.0019 & 0.0009 & $0.0034^{* * * *}$ & 0.0026 \\
\hline 8th Dec & $0.0097 *$ & $0.0036^{*}$ & $0.0059^{* *}$ & 0.0018 & 0.0026 & $0.0071^{* * * *}$ & 0.0070 & 0.0026 & 0.0020 & $0.0033^{* * * *}$ & 0.0001 \\
\hline 9th Dec & $0.0115^{* *}$ & $0.0050^{* * *}$ & $0.0059^{*}$ & 0.0050 & 0.0037 & $0.0074^{* * * *}$ & 0.0049 & $0.0048^{* * *}$ & $0.0024^{*}$ & $0.0029^{* * *}$ & $0.0038^{* *}$ \\
\hline 10th Dec & $0.0142^{* *}$ & $0.0046^{* * *}$ & $0.0063^{* *}$ & 0.0026 & $0.0176^{*}$ & $0.0056^{* * * *}$ & 0.0042 & $0.0106^{* * *}$ & 0.0048 & $0.0025^{* * *}$ & $0.0023^{*}$ \\
\hline $\mathrm{ARCH}$ & $0.2329^{* * * *}$ & $0.4257^{* * * *}$ & $0.2304 * * * *$ & $0.3820^{* * * *}$ & $0.3077^{* * * *}$ & $0.2401 * * * *$ & $0.1659^{* * * *}$ & $0.2767^{* * * *}$ & $0.4985^{* * * *}$ & $0.2736^{* * * *}$ & $0.3193^{* * * *}$ \\
\hline GARCH & $0.7721^{* * * *}$ & $0.6312^{* * * *}$ & $0.7925^{* * * *}$ & $0.6503^{* * * *}$ & $0.7033^{* * * *}$ & $0.7067^{* * * *}$ & $0.8455^{* * * *}$ & $0.7540^{* * * *}$ & $0.5746^{* * * *}$ & $0.6767^{* * * *}$ & $0.7326^{* * * *}$ \\
\hline Constant & $0.0000^{* * * *}$ & $0.0000^{* * * *}$ & $0.0000^{* * * *}$ & $0.0000^{* * * *}$ & $0.0000^{* * * *}$ & $0.0000^{* * * *}$ & $0.0000^{* * * *}$ & $0.0000^{* * * *}$ & $0.0000^{* * * *}$ & $0.0000^{* * * *}$ & $0.0000^{* * * *}$ \\
\hline & LTC & NEO & OMG & QSH & QTM & RRT & SAN & XMR & XRP & YYW & ZEC \\
\hline$R_{t-1}$ & $0.0315^{* * * *}$ & 0.0008 & 0.0043 & $-0.1814^{* * * *}$ & $-0.0678^{* * * *}$ & $-0.2977^{* * * *}$ & $-0.1360^{* * * *}$ & $0.0472^{* * * *}$ & $\frac{1 \pi}{-0.0087}$ & $-0.1885^{* * * *}$ & 0.0185 \\
\hline$R_{t-2}$ & -0.0053 & $-0.0265^{* * * *}$ & -0.0127 & $-0.0459^{* *}$ & 0.0020 & $0.1924^{* * *}$ & $-0.0405^{* * * *}$ & $-0.0175^{*}$ & $-0.0662 * * * *$ & $-0.0735 * * * *$ & 0.0065 \\
\hline$R_{t-3}$ & $-0.0424^{* * * *}$ & 0.0001 & -0.0079 & $-0.0331^{*}$ & 0.0148 & $0.1500^{* * *}$ & -0.0177 & -0.0075 & $0.0146^{* * *}$ & -0.0142 & $-0.0299^{* *}$ \\
\hline$R_{t-4}$ & $-0.0205^{* *}$ & $-0.0274^{* * * *}$ & $-0.0177^{*}$ & $-0.0471^{* *}$ & $-0.0547^{* * * *}$ & $0.0873^{* * * *}$ & $0.0263^{* *}$ & -0.0200 & $-0.0419 * * *$ & -0.0198 & -0.0039 \\
\hline$R_{t-5}$ & 0.0084 & 0.0010 & -0.0137 & $-0.0464^{* *}$ & 0.0056 & $0.0908^{* * * *}$ & -0.0031 & $0.0058^{*}$ & -0.0010 & 0.0161 & -0.0125 \\
\hline$R_{t-6}$ & $-0.0145 * *$ & $-0.0230^{* *}$ & -0.0092 & $0.0211^{*}$ & 0.0073 & $0.0960^{* * * *}$ & $0.0267^{* * *}$ & 0.0244 & $0.0225 * *$ & 0.0140 & -0.0119 \\
\hline$R_{t-7}$ & -0.0061 & $0.0165 *$ & -0.0143 & $0.0247 *$ & $-0.0154^{* *}$ & $0.0567^{* * * *}$ & $-0.0242^{* *}$ & $0.0102^{* * *}$ & -0.0013 & 0.0217 & $-0.0343^{* * *}$ \\
\hline$R_{t-8}$ & -0.0002 & 0.0065 & $0.0176^{*}$ & -0.0296 & 0.0018 & $0.0196^{* * *}$ & 0.0067 & 0.0013 & -0.0059 & 0.0127 & 0.0030 \\
\hline BTC & $0.5239^{* * * * *}$ & $0.2186 * * * *$ & $0.1686^{* * * * *}$ & $0.4580^{* * *}$ & $0.4211^{* * * *}$ & $0.2051 * * * *$ & $0.3772^{* * * * *}$ & $0.5296^{* * * *}$ & $0.2970^{* * * *}$ & $1.0590^{* * * *}$ & $0.4368^{* * * *}$ \\
\hline VSTOXX & $0.0001^{* * * *}$ & 0.0000 & 0.0001 & 0.0001 & 0.0001 & $0.0005^{* * * *}$ & -0.0002 & 0.0001 & -0.0001 & 0.0000 & $0.0001 *$ \\
\hline ETH & $0.4238^{* * * *}$ & $0.6082^{* * *}$ & $0.5489^{* * *}$ & $0.3454^{* * *}$ & $0.5069^{* * * *}$ & 0.0029 & $0.6136^{* * *}$ & $0.3155^{* * *}$ & $0.4965^{* * * *}$ & - & $0.3681^{* * * * *}$ \\
\hline LTC & & $0.3233^{* * * *}$ & $0.2640^{* * * *}$ & $0.0874^{* * * *}$ & $0.1049^{* * * *}$ & $0.1267^{* * * *}$ & $0.0736^{* * * *}$ & $0.1285^{* * * *}$ & $0.1717^{* * * *}$ & 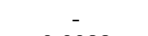 & $0.1605^{* * * *}$ \\
\hline 1st Dec & 0.0003 & 0.0003 & 0.0051 & 0.0096 & $0.0102^{*}$ & 0.0000 & 0.0001 & 0.0001 & 0.0019 & 0.0033 & 0.0011 \\
\hline 2nd Dec & 0.0017 & 0.0088 & 0.0056 & 0.0017 & 0.0019 & 0.0011 & 0.0001 & 0.0005 & $0.0031 *$ & 0.0035 & 0.0021 \\
\hline 3rd Dec & 0.0016 & & 0.0014 & & 0.00 & 0.0005 & & & & & 0.0014 \\
\hline 4th I & 0.0017 & & & & & 0.0 & & & & & \\
\hline 5th Dec & $0.0040^{* * * *}$ & & & 0.0 & & 0.00 & & & & & \\
\hline 6th Dec & $6 * * *$ & 0. & & 0. & & 0. & & 0. & & 0.8 & $29^{*}$ \\
\hline 7th Dec & & & & & & & & & & & $48^{*}$ \\
\hline 8th Dec & & 0.0 & & & & & & & & & $0.0051^{* *}$ \\
\hline 9th Dec & $0.0082^{* * *}$ & 0.0009 & 0.0003 & 0.0038 & $0.0071 *$ & $0.0130 * * *$ & 0.0007 & 0.0009 & 0.0004 & 0.0028 & $0.0055^{* *}$ \\
\hline 10th Dec & $0.0106^{* * * *}$ & 0.0020 & 0.0050 & 0.0045 & $0.0102 *$ & $0.0318^{* * *}$ & 0.0084 & 0.0010 & $0.0012^{*}$ & 0.0033 & $0.0090^{*}$ \\
\hline $\mathrm{ARCH}$ & $0.5277^{* * * *}$ & $0.4323^{* * * *}$ & $0.2830 * *$ & $0.1354 * * * *$ & $0.1748^{*}$ & $0.2007^{* * * *}$ & 0.517 & 0.3022 & 0.5640 & $0.1538^{* * * *}$ & $0.3230^{* * * *}$ \\
\hline GARCH & $0.5798^{* * * *}$ & $0.6160^{* * * *}$ & $0.7135^{* * * *}$ & $0.8410^{* * * *}$ & $0.8567^{* * * *}$ & $0.7218^{* * * *}$ & $0.5580^{* * * *}$ & $0.6635^{* * * *}$ & $0.4900^{* * * *}$ & $0.8670^{* * * *}$ & $0.7075^{* * * *}$ \\
\hline Constant & $0.0000^{* * * *}$ & $0.0000^{* * * *}$ & $0.0000^{* * * *}$ & $0.0000^{* * * *}$ & $0.0000^{* * * *}$ & $0.0001 * * * *$ & $0.0000^{* * * *}$ & $0.0000^{* * * *}$ & $0.0000^{* * * *}$ & $0.0000^{* * * *}$ & $0.0000^{* * * *}$ \\
\hline
\end{tabular}

Note: The presented analysis was conducted using 30 minute data between midnight on 22 June 2017 and 11:30 pm on 23 June 2018. ****, ***, ** and ${ }^{*}$ indicates statistical significance at the $0.1 \%, 1 \%, 5 \%$ and $10 \%$ levels respectively. 
Table 3: Cryptocurrency performance during differing deciles of VSTOXX volatility

\begin{tabular}{|c|c|c|c|c|c|c|c|c|c|c|c|}
\hline & $\begin{array}{c}\text { AVT } \\
1^{* * * *}\end{array}$ & $\mathrm{BCH}$ & BTC & BTG & DAT & $\mathrm{DSH}$ & EDO & $\mathrm{EOS}$ & ETH & ETP & IOT \\
\hline$R_{t-1}$ & $-0.1711^{* * * *}$ & & -0.0030 & $-0.0411^{* *}$ & $-0.0600^{* *}$ & $0.0437^{* * * *}$ & $-0.0998^{* * * *}$ & $-0.0354^{* *}$ & -0.0044 & $-0.1057^{* * * *}$ & $0.0369^{* *}$ \\
\hline$R_{t-2}$ & $-0.1464^{* * * *}$ & -0.0170 & $0.0318^{*}$ & 0.0047 & $-0.0611 * *$ & $-0.0239^{*}$ & -0.0119 & $-0.0060^{* *}$ & 0.0010 & -0.0411 & $-0.0291 * *$ \\
\hline$R_{t-3}$ & $-0.1326^{* * * *}$ & $-0.0321^{* *}$ & -0.0060 & -0.0244 & $-0.0685^{* * * *}$ & $-0.0422 * * * *$ & -0.0166 & $0.0001^{* * * *}$ & $-0.0211^{* *}$ & 0.0077 & $0.0268^{* *}$ \\
\hline$R_{t-4}$ & -0.0275 & $0.0301^{* *}$ & 0.0133 & 0.0050 & -0.0006 & -0.0041 & $-0.0717^{* * * *}$ & 0.0055 & -0.0101 & -0.0201 & 0.0026 \\
\hline$R_{t-5}$ & -0.0082 & -0.0216 & 0.0102 & $-0.0385^{* *}$ & $-0.0667^{* * *}$ & $0.0285^{* *}$ & -0.0224 & -0.0046 & 0.0066 & $0.0474^{* *}$ & 0.0168 \\
\hline$R_{t-6}$ & 0.0034 & $0.0480^{* * * *}$ & $0.0226^{* *}$ & 0.0130 & $-0.0717^{* * *}$ & $-0.0284^{* *}$ & -0.0020 & $-0.0028^{*}$ & 0.0075 & -0.0247 & $0.0711 * * *$ \\
\hline$R_{t-7}$ & -0.0304 & -0.0142 & -0.0008 & $-0.0321^{* *}$ & 0.0031 & $0.0227^{*}$ & -0.0049 & -0.0175 & $-0.0273^{* *}$ & $0.0550^{* *}$ & $-0.0397^{* * *}$ \\
\hline$R_{t-8}$ & -0.0274 & -0.0105 & -0.0142 & -0.0083 & 0.0206 & $-0.0332^{* *}$ & -0.0079 & 0.0194 & $0.0346^{* * *}$ & 0.0069 & 0.0206 \\
\hline BTC & $0.4660^{* * * *}$ & $0.5814^{* * * *}$ & & $0.5109^{* * * *}$ & $0.6116^{* * * *}$ & $0.3551 * * *$ & $0.6176 * * * *$ & $0.6029 * * * *$ & $0.5126^{* * * *}$ & $0.6364 * * * *$ & $0.4817^{* * * *}$ \\
\hline VIX & 0.0004 & -0.0002 & $0.1808^{* * *}$ & 0.0004 & -0.0003 & -0.0001 & $0.0005^{*}$ & $0.0000^{* *}$ & $0.0000^{*}$ & -0.0004 & -0.0001 \\
\hline ETH & $0.1626^{* * * *}$ & $0.1073^{* * * *}$ & $0.4423 * * * *$ & $0.2655^{* * * *}$ & $0.1576^{* * * *}$ & $0.1844^{* * * *}$ & $0.1799^{* * *}$ & $0.2911^{* * *}$ & (2) & $0.1601 * * * *$ & $0.3346^{* * * *}$ \\
\hline LTC & -0.0135 & $0.2906 * * *$ & -0.0002 & $0.1644 * * *$ & $0.1681^{* * *}$ & $0.2934^{* * * *}$ & $0.1047^{* *}$ & $0.2052^{* * * *}$ & $0.3589^{* * * * *}$ & $0.2690^{* * *}$ & $0.2596^{* * * *}$ \\
\hline 1st Dec & 0.0002 & 0.0001 & $0.0003^{*}$ & 0.0001 & $0.0004^{* *}$ & 0.0001 & 0.0002 & 0.0002 & 0.0001 & $0.0001^{* * *}$ & 0.0014 \\
\hline 2nd Dec & 0.0003 & $0.0006^{*}$ & 0.0000 & 0.0003 & $0.0005^{* *}$ & 0.0001 & 0.0001 & 0.0004 & 0.0004 & $0.0010 * *$ & 0.0005 \\
\hline 3rd Dec & 0.0003 & 0.0001 & 0.0001 & 0.0002 & 0.0006 & 0.0002 & 0.0021 & $0.0007^{*}$ & 0.0000 & $0.0027^{*}$ & 0.0007 \\
\hline 4th Dec & 0.0003 & 0.0001 & 0.0003 & 0.0003 & 0.0020 & 0.0002 & 0.0030 & 0.0002 & 0.0004 & 0.0025 & 0.0018 \\
\hline 5th Dec & 0.0002 & 0.0002 & 0.0004 & 0.0005 & 0.0003 & 0.0009 & $0.0030^{* *}$ & 0.0003 & 0.0000 & 0.0004 & 0.0035 \\
\hline 6th Dec & 0.0002 & 0.0001 & 0.0001 & 0.0001 & 0.0001 & 0.0006 & 0.0012 & 0.0000 & 0.0001 & 0.0002 & 0.0031 \\
\hline 7th Dec & 0.0003 & $0.0004^{*}$ & $0.0002^{* *}$ & 0.0008 & 0.0000 & 0.0004 & 0.0002 & $0.0003^{*}$ & 0.0002 & 0.0000 & 0.0036 \\
\hline 8th Dec & 0.0003 & $0.0005^{*}$ & $0.0005^{*}$ & 0.0007 & $0.0019^{* *}$ & 0.0010 & 0.0013 & $0.0047^{* * * *}$ & $0.0007^{* *}$ & 0.0018 & 0.0008 \\
\hline 9th Dec & 0.0004 & $0.0005^{*}$ & $0.0018^{* *}$ & $0.0026^{* *}$ & $0.0012^{*}$ & 0.0021 & 0.0013 & $0.0008^{* * * *}$ & $0.0021^{* * * *}$ & $0.0034^{* *}$ & 0.0009 \\
\hline 10th Dec & 0.0005 & $0.0017^{*}$ & $0.0012^{*}$ & $0.0028^{*}$ & 0.0015 & 0.0016 & $0.0048^{*}$ & $0.0026^{* *}$ & $0.0015^{* * * *}$ & $0.0041^{* * *}$ & 0.0009 \\
\hline $\mathrm{ARCH}$ & $0.3202^{* * * *}$ & $0.4955^{* * * *}$ & $0.4279^{* * * *}$ & $0.2657^{* * * *}$ & $0.6954^{* * * *}$ & $0.2685^{* * * *}$ & $0.1962 * * * *$ & $0.5051 * * * *$ & $0.5950^{* * * *}$ & $0.1817^{* * * *}$ & $0.6013^{* * * *}$ \\
\hline GARCH & $0.6406^{* * * *}$ & $0.4487^{* * * *}$ & $0.5450 * * * *$ & $0.7462^{* * * *}$ & $0.3024^{* * * *}$ & $0.7062^{* * * *}$ & $0.8028^{* * * * *}$ & $0.4806^{* * * *}$ & $0.3210^{* * * *}$ & $0.8168^{* * * *}$ & $0.3974^{* * * *}$ \\
\hline Constant & $0.0000^{* * * *}$ & $0.0000^{* * * *}$ & $0.0000^{* * * *}$ & $0.0000^{* * * *}$ & $0.0001^{* * * *}$ & $0.0000^{* * * *}$ & $0.0000^{* * * *}$ & $0.0000^{* * * *}$ & $0.0000^{* * * *}$ & $0.0000^{* * * *}$ & $0.0000^{* * * *}$ \\
\hline & LTC & NEO & OMG & QSH & QTM & RRT & SAN & XMR & XRP & YYM & ZEC \\
\hline$R_{t-1}$ & $0.0371^{* * * *}$ & 0.0093 & 0.0011 & $-0.1190^{* * *}$ & $-0.0408^{* *}$ & $-0.3352^{* * * *}$ & $-0.1286^{* * * *}$ & $0.0649^{* * * *}$ & $-0.0313^{* * * *}$ & $-0.1615^{* * *}$ & $0.0230^{*}$ \\
\hline$R_{t-2}$ & $-0.0240^{* *}$ & $-0.0316^{* *}$ & -0.0047 & -0.0232 & -0.0129 & $-0.1733^{* * *}$ & $-0.0367^{* *}$ & $-0.0409 * *$ & $-0.0302^{* * * *}$ & $-0.0743^{* * *}$ & -0.0019 \\
\hline$R_{t-3}$ & $-0.0341^{* * * *}$ & 0.0096 & $-0.0295 *$ & -0.0218 & $-0.0360 * *$ & $-0.1124^{* * *}$ & $-0.0722^{* * *}$ & -0.0061 & $-0.0573^{* * * *}$ & 0.0126 & 0.0038 \\
\hline$R_{t-4}$ & $-0.0274^{* *}$ & $-0.0172^{* *}$ & 0.0127 & -0.0339 & $-0.0204^{*}$ & $-0.0742^{* * *}$ & $-0.0347^{*}$ & $\begin{array}{l}-0.0091 \\
-0.0094\end{array}$ & $-0.0503^{* * *}$ & $\begin{array}{l}0.0120 \\
-0.0072\end{array}$ & $\begin{array}{l}0.0038 \\
0.0037\end{array}$ \\
\hline$R_{t-5}$ & $-0.0191 *$ & $0.0398^{* * *}$ & -0.0094 & -0.0100 & $-0.0294^{* *}$ & $-0.0879^{* * *}$ & 0.0125 & -0.0079 & $0.0184^{*}$ & $0.0421^{*}$ & $-0.0386^{* * *}$ \\
\hline$R_{t-6}$ & $-0.0343^{* * * *}$ & -0.0220 & $-0.0287^{*}$ & 0.0005 & $-0.0267^{* *}$ & $-0.0982^{* * *}$ & $0.0469^{* * *}$ & 0.0032 & 0.0067 & 0.0198 & $-0.0350^{* * *}$ \\
\hline$R_{t-7}$ & 0.0047 & -0.0087 & 0.0135 & 0.0010 & $-0.0400 * *$ & $-0.0689^{* * *}$ & 0.0087 & $0.0279^{* *}$ & -0.0044 & 0.0009 & 0.0108 \\
\hline$R_{t-8}$ & $-0.0275^{* *}$ & $-0.0226^{*}$ & 0.0049 & -0.0083 & -0.0247 & $0.0266^{*}$ & $0.0592^{* * *}$ & 0.0071 & $-0.0218^{*}$ & 0.0307 & -0.0160 \\
\hline BTC & $0.5452 * * * *$ & $0.1714^{* * * * *}$ & $0.2943 * * * *$ & $0.5915 * * * *$ & $0.4778^{* * * * *}$ & $0.4311 * * * *$ & $0.4044 * * * *$ & $0.5439 * * * *$ & $0.3183^{* * * * *}$ & $0.5754^{* * * *}$ & $0.5017 * * * *$ \\
\hline VIX & $0.0003^{* *}$ & $-0.0004^{* *}$ & -0.0004 & 0.0004 & 0.0000 & $0.0008^{* *}$ & $0.0007^{* * * *}$ & 0.0000 & -0.0002 & 0.0003 & 0.0000 \\
\hline ETH & $0.4066^{* * *}$ & $0.5361^{* * * *}$ & $0.6935^{* * *}$ & $0.2040^{* * * *}$ & $0.4586^{* * *}$ & $0.2787^{* * * *}$ & $0.6290 * * * *$ & $0.4247^{* * * *}$ & $0.4792^{* * * * *}$ & $0.3974^{* * * *}$ & $0.4560^{* * * *}$ \\
\hline LTC & 0.4000 & $0.3702 * * * *$ & $0.0855^{* * * *}$ & $0.1676^{* * * *}$ & $0.1506^{* * *}$ & $-0.1076^{* *}$ & $0.0960^{* * * *}$ & $0.0326 * *$ & $0.1787^{* * * *}$ & 0.0614 & $0.0505^{* * *}$ \\
\hline 1st Dec & $0.0013^{*}$ & $0.0008^{* *}$ & $0.0025 *$ & $0.0033^{*}$ & 0.0001 & $0.0004^{*}$ & 0.0001 & 0.0010 & 0.0001 & 0.0011 & 0.0001 \\
\hline 2nd Dec & 0.0000 & $0.0015^{* *}$ & 0.0012 & $0.0027^{* *}$ & 0.0001 & 0.0008 & 0.0018 & $\begin{array}{l}0.00109 \\
0.0009\end{array}$ & $0.0011^{* *}$ & $0.0036^{* *}$ & $\begin{array}{l}0.00002 \\
0.0002\end{array}$ \\
\hline 3rd Dec & 0.0006 & $0.0006^{*}$ & 0.0010 & $0.0036^{* * *}$ & 0.0006 & 0.0041 & 0.0000 & 0.0012 & $0.0012^{* *}$ & $0.0025^{* * *}$ & 0.0005 \\
\hline 4th Dec & 0.0007 & $0.0009^{*}$ & 0.0008 & 0.00 & 0.0 & 0.0005 & 0.0011 & $0.0009^{* *}$ & 0.0 & $2 * *$ & $0.0013^{*}$ \\
\hline 5th Dec & 0.0009 & 0.0002 & $0.0017^{*}$ & 0.0 & 0.0 & 0.0022 & $0.0009^{*}$ & $0.0015^{* * *}$ & & 0.0 & $0.0011^{*}$ \\
\hline 6th Dec & 0.0002 & 0.0 & $16^{*}$ & 0.0 c & 0.0 & 0.0004 & $0.0023^{* * *}$ & $5 * *$ & 0.0002 & 0.0010 & $0.0010^{* *}$ \\
\hline 7th Dec & $0.0004^{*}$ & & ** & & 0.0002 & 0.0 & $0.0044^{* * * *}$ & *** & 0.0000 & 0.0020 & $0.0012^{*}$ \\
\hline 8th Dec & $0.0006^{*}$ & 0.0004 & 0.001 & 0.0017 & 0.0001 & 0.0012 & 0.00 & $0.0017^{* *}$ & 0.0004 & 0.0002 & 0.0008 \\
\hline 9th Dec & $0.0011 *$ & $0.0018^{*}$ & $0.0015^{* *}$ & 0.0004 & 0.0003 & 0.0012 & $0.0055^{* * * *}$ & $0.0023^{* *}$ & 0.0000 & $0.0024^{* *}$ & 0.0006 \\
\hline 10th Dec & $0.0033^{* *}$ & $0.0040^{* *}$ & $0.0027^{*}$ & 0.0037 & 0.0008 & 0.0060 & $0.0080^{* * * *}$ & $0.0012^{*}$ & 0.0011 & $0.0032^{*}$ & 0.0009 \\
\hline $\mathrm{ARCH}$ & $0.7296 * * * *$ & $0.6895^{* * * *}$ & $0.0112 * *$ & $0.2827^{* *}$ & 0.1793 & $0.3314 * * * *$ & $0.9014^{*}$ & $0.4636^{* * * *}$ & $0.6817^{* * * *}$ & $0.2805^{* * * *}$ & $0.4626^{* * * *}$ \\
\hline GARCH & $0.4499 * * * *$ & $0.2342^{* * * *}$ & $1.0188^{* * * *}$ & $0.5558^{* * * *}$ & $0.7729^{* * * *}$ & $0.5749 * * * *$ & $0.2967 * * * *$ & $0.4428^{* * * *}$ & $0.3594^{* * * *}$ & $0.7135^{* * * *}$ & $0.5774^{* * * *}$ \\
\hline Constant & $0.0000^{* * * *}$ & $0.0000^{* * * *}$ & $0.0003^{* * * *}$ & $0.0000^{* * * *}$ & $0.0000^{* * * *}$ & $0.0001 * * * *$ & $0.0000^{* * * *}$ & $0.0000^{* * * *}$ & $0.0000^{* * * *}$ & $0.0000^{* * * *}$ & $0.0000^{* * * *}$ \\
\hline
\end{tabular}

Note: The presented analysis was conducted using 30 minute data between midnight on 22 June 2017 and 11:30 pm on 23 June 2018. ****, ***, ** and ${ }^{*}$ indicates statistical significance at the $0.1 \%, 1 \%, 5 \%$ and $10 \%$ levels respectively. 